\title{
The Reform and Innovation of Mock Trial
}

\author{
Liu $\mathrm{Na}^{1}$ \\ ${ }^{1}$ Sichuan Agricultural University, \\ Sichuan, China
}

\begin{abstract}
Law education is not only the theoretical knowledge education ,but also the professional education with strong practicality and applied education.Practical teaching of mock trial is an important way to improve the students' ability of participating in the law practice.China's current legal system of the curriculum is not perfect enough, and students' initiative and enthusiasm of participating in the law practice is bad.This article made an analysis about the curriculum provision and the curriculum control,trying to give some advice of the practical teaching of mock trial's reform and innovation.
\end{abstract}

Keywords: mocktrial curriculum provision, reform, innovation.

\section{INTRODUCTION}

Simulation is a virtual process of real thing or process, mock trial is a simulation of court scene or program. mock trial is a practical teaching method, different students play roles injudge,procurator,parties and other litigants, doing Mock trial toward real or virtual law cases according to legal procedures in the virtual under the auspices of the judge.

Mock trial,also named mock court." mock court" imported goods,also names model court,which originally came from the moot court in American law schools. Since 1930s, it has been translated into "mock court" by China.Mock trial is a necessary lesson of law major's practical teaching,but at present our country haven't had a unified and complete system design toward the course name, course system and specific implementation system,even the textbooks of practical teaching of mock trial.

Practical teaching of Mock trial emphasizes students' abilities to participating practice on the basis of theoretical knowledge.As what Edgar.Boden hammer,anAmerican legal philosopher,said,the person can not be an excellent legal worker if he is only a craftsman of law and only know the rules of law procedures and positive law.Law education is not only the theoretical knowledge education ,but also the professional education with strong practicality and applied education.The combination of practicalness, professionalism, academism and elitism is the basic value orientation of law education.Mock trial can achieve the educational goal of unity of theory and practice by letting students deeply involved,applying the theoretical knowledge of law and judicial basic skills to practice. The practice of legal cases can improve students' judicial basic skills ,interests in learning and initiative learning attitude.Further more, it can let them deal with complicated and event-intense problems,form and evaluate solutions,rethink the whole law career,explore the concept and method related to legal system of substance and procedure justice On the basis of the empirical.

\section{The situation of mock trial practice teaching}

\section{1.narrow range of case selection}

\subsection{1.network selection}

In this open space of network,Government affairs, news focus or ordinary people's livelihood to the mock trial provides a true opportunity to experience the reality of the law,it can inspire students interests and enthusiasm to participate in social and legal practice.However, the network is a fragment of the information provided is not comprehensive, it's impossible to show all details associated with the law applicable completely in mock trial .The Supreme People's Court as a class and other specialized legal site can also search for existing jurisprudence,but there is small number of cases to show ,and materials are not complete,Often only the final judge, other materials needed in the trial process nowhere to search.

\subsubsection{Create a script}

Create scripts can be more comprehensive to complete the design of Simulation trial. And the logically is perfect, but put too much attention to logical reasoning and ignored the real experience of life, because of students in 
the simulation with no real situation and real experience, they are likely dull, and lack of vitality, they are unable to accurately understand the true essence of the law. Because of design, It's easy to make students create a script as a performance of the script, it's more like a performance, and it's lack of the seriousness of the law.

\subsubsection{The simulation trial teaching material}

simulation trial teaching material not only provides a comprehensive case material, but also provides the simulation trial of general procedure knowledge, students' roles, simulation process-related control material, that is the first choice of simulation trial teaching.

But at the moment, the teaching materials about the simulations are very limited and the good and bad are intermingled, and the simulation trial materials which are provided by the case material are not enough neither, there are no more choices.

\subsection{The Weakness of Students' Participation}

The conscious of participation in student awareness is $n$ ot strongthe practice of mock trial is not so active and ini tiative, which affect the teaching quality of mock trial and can't realize the teaching goals. The reasons are as follow s.

\subsubsection{The setting of law course system prefers to theor $\mathrm{y}$ than practice}

According to the reality, no matter to the law college or the students, the key to determine the direction of student 's employment and the quality is to pass the exam for the 1 egal profession--National Judicial Examination. The passi ng rate of National Judicial Examination is a strong evide nce to judge the quality of law education. The National Ju dicial Examination is also the first thing for students to op en their door of career. Even though the National Judicial Examination has some exam for the ability of practice, the exam is mainly about the theory. Nowadays, the setting o $\mathrm{f}$ law course system which has a preference of theory is pl ain truth in our country. Compared with other countries' 1 aw education, let's take Harvard University as an example , the training of the professional ability is one of the chara cteristics.

There are 111 courses are mainly about the research learning Which takes the form of classroom instruction and has taken up $39.5 \%$ of the whole courses. The course that takes the research learning as the main for $\mathrm{m}$ always needs the help of mock court to realize the teac hing goal. And the students' have the enthusiasm to partic ipate the class.

\subsubsection{The limitation of material affected the initiative of students}

Given the limitations of simulation trial case selection scope, teachers usually specified cases in order to ensure the simulation trial case materials comprehensive, which makes students lack of initiative in case selection. The case that assigned by teacher may not be able to stimulate students' interests in thinking of it, thus contributing the students' lack of enthusiasm in the participation. In terms of students' own script, due to the lack of authenticity, in addition to the" Method of teaching the court procedures, rules of evidence, the court debate and the concrete trial system through the virtual civil or criminal cases. Since it is a virtual trial, simulate the court's decision is not binding." Students lost the real social experience, especially the real social identity gained from the recognized simulation trial results, which may lead to their negativity in coping with trial practice. The author has attempt to give students the rights to choose simulation case. They are very seriously to collect materials, especially those related to the student groups. The effect of the simulation trial got obvious improvement. Everyone is very positive.

\subsubsection{Form overweighs process in the simulation trial teaching design}

On the present curriculum of simulation trial practice teaching, general method is attaching it to a theoretical course. There is no independent, special practice system charged by the specialized teacher and the instructor is usually the one who teaches the theoretical course. Due to the scarce of instructor, coupled with the their heavy teaching task, the guidance and management of students' mock trial preparation process is not enough. Some students without sufficient ability or self-consciousness will not do their best in the course. In terms of assessment in simulation trial, it is on the final case simulation trial with less concern on process factor; Without elaborate appraisal content, assessment is not comprehensive and reasonable; The standard is not clear. Examination rights are held by the instructor and the assessment results are finally decided by the guide teacher. If the wide standard is taken, there would be an happy ending. But for students, whether they are careful preparation and positive participation or not, it is ok to pass the final performance. On this circumstances, who will be actively involved in teaching practice?

\subsection{Lack of instructor capability}

Currently teaching practice mock trial work is mainly $r$ esponsible for a door from the corresponding theory class 
teacher as mentor, some teachers both lawyers, jurors, or people's supervisors and other people's practical identity, which enhances the authenticity and realistic simulation o $\mathrm{f}$ the trial process There are a great help, but also allows st udents to obtain relevant guidance in the preparation proc ess. But there are some teachers do not have any experien ce in legal practice, a certain perspective, the mock trial e xperience and students like they lack.In such a situation, i s not conducive to student legal ethics and professional co nduct vocational training, law students who help to shape the career rational.

\section{Reform and innovation in teaching college mock tria 1 practice}

\subsection{The content of the curriculum system in strengthen ing the practice of law set}

Although it is generally agreed that education is an elite education law, "but elite education does not mean $\mathrm{m}$ ere knowledge exploration and scientific research, practic al and vocational ability to locate legal education has been placed in the first position. If a law graduates connection to be a party, concentrated focus and difficult issue, assu mptions and basic skills are not envisaged that such legal education of its poor quality, the slim prospects of it imagine. "

The current curriculum system should be set up to strengthen the legal profession legal ability and training c ourses designed to improve the proportion of prac-tical te aching curriculum Law. Correspondingly, the possible establishment of a separate curriculum practice by the person responsible.

\subsection{Improve the teaching design mock trial}

\subsubsection{Broaden the range of options mock trial case, the trial of cases reinforce the authenticity and inspire stu dents to participate in the initiative.}

Case Selection in addition to the traditional chann els, but also should be possible to exploit the existing pote ntial resources.

First, engage in legal practice teacher at acquisition cases. In this case the selected case is true, the material is relatively complete, and the instructor can do more target ed guidance, higher student participation in the initiative. However, when selecting cases should comply with the pr ovisions of the law, and the parties have to communicate.

Second, look for the case from a legal advisory practice. Some colleges and universities opened a law pra ctice consulting practice courses on social and legal issues for eliminating A puzzled students theoretical knowledge in favor of legal thinking, more important is that these ca ses are firsthand material from real life, almost all pendin $\mathrm{g}$ cases By the form of a mock trial helps students to parti cipate fully in the practice of law, to enable students to ac quire selfaffirmation and social identity, inspire enthusias m to study law.

Third, in cooperation with the practice of seeking cases.Many law school system and the judicial practice de partments to establish a cooperative relationship, such as $\mathrm{t}$ eaching practice base. To improve student engagement an $\mathrm{d}$ enhancing strong student community ase-nse of commu nity involvement, can get in touch with teaching practice unit within the scope permitted by law to provide a simple request for their case, and to give proper guidance.The ch oice of such cases arouse students' active thinking virtuall $y$ cases, actively participate in the trial of enthusiasm, bec ause they have the potential sectors and legal practice trial s to compare. Where the author was on the court conclude $\mathrm{d}$ the school together real criminal cases were simulated $\mathrm{u}$ nder full range of materials, the students were actively inv olved in the simulation preparation and careful thought, th e effect is very obvious.

Fourth,Practice via competition.Through designing and participating the competition related to law to tap the enthusiasm of students.

With a debate for example, which was held between the laws institute of our university and the people's procuratorate, to a certain extent, encourage students to initiatively study case and actively participate the Simulation. Meanwhile, using the moot court competition of college students in Sichuan Province and a series of selection among the institute, combining the request that events select cases, both strengthen the students' theoretical knowledge and skills.

\subsubsection{Strengthen the process control of the Simulation Trial}

On the organization of the teaching activity, in terms of basic principles of pedagogy, we should regard the student as the main body while the whole procedure must be dominated by the teacher. Teachers just need to divide work roughly and make students clear about their own tasks but the concrete preparation work should be completed by students themselves. In addition, teachers should irregularly take measures to check, to visit and suggest so as to ensure the quality of the preparation process.

Generally the plan can be taken as follows:

Firstly, ascertain the case we will work for and the specific number of participated people.Secondly, get ready to group trial students and select a leader, who can be also appointed by teacher, of each group. Take the criminal simulation case for example--according to the court's participation, students are divided into trial 
group ,public prosecution group and advocacy group ,what's more, witnesses, expert witnesses, bailiffs can fit into the corresponding group or can form a group named "others".Thirdly, the instructor can give some hints about what should be focused on to each team and ask each group to make a record of every preparation including attendance, preparation, content, group evaluation .Until the curriculum assessment the record will be handed over and evaluated by the team leader according to the performance of the group members then the leader will give a score for teacher's reference.

Finally, in order to achieve real effect of the trial, we advise students not to practice together before the simulation trial, just separately prepare and the whole group practice together for final trial. This action, which makes each group have no information about others', including focus of trial, is helpful to improve the student's ability of on-the-spot solving legal problems .

During trial preparation process, teachers should randomly check every team preparations at any time. After the Simulation Trial, through self and mutual evaluation of student as well as teachers comments, we pointed out the problems in Simulation Trial timely. Teachers can ask students to write comments, to summarize Simulation Trial work.

\subsubsection{Refine Simulation Trial examination and standard.}

The assessment results of Simulation Trial should based on scientific and comprehensive evaluation criteria, namely, teachers cannot give evaluation freely. Simulation trial is the embodiment of the students' comprehensive ability of law, the abilities include not only understanding of the legal theory knowledge but also the grasp of practical knowledge, especially the understanding of the law professional quality.

Simulation-Trial assessment should include to three stages--preparation process, Simulation process, Summing up. The details of assessment are made up by : (1) The attendance of preparation phase (2) The performance of each event which implies the quality and level of documents production of each corresponding role (3) The basic process of trial and the etiquette during the simulation, such as, whether the student acquired the knowledge of trial process and the use of court language is accurate, etc.(4)whether the summing up is objective and with a serious attitude, etc.

\subsubsection{Improve the level of the instructor}

Simulation- trial-practice teaching task should be possibly arranged to some teachers who have some practical law experience. Meanwhile, enhance the cooperation with some practical departments and probably hire some experienced people with higher levels of education as a practical teaching instructor; In judicial practice, we can also invite some relative people who working for the co-department to give some advice, for example, when it comes to a criminal simulation trial cases, we can invite the people's procuratorate of prosecutors to guide for the simulation of public prosecution.

\section{Conclusions}

Given the practical teaching is an important means of legal education, strengthening the practice teaching link is the development direction of law education reform. We should guarantee simulation trial activities via system, the corresponding personnel and material so as to effectively and rapidly promote the teaching quality for law students.

\section{References}

[1] Bodenheimer:"jurisprudence:legalphilosophy and legal methods",Translated by Deng Zheng, China University of Political Science Press, pp. 531,2004.

[2] Xigen Wang:"America's latest legal education reform and its Enlightenment - Harvard University Law School as a sample” ,Law Journal, page 37, the first one, 2010.

[3] Xigen Wang:"The latest reform of legal education in the United States and its Enlightenment - Harvard University Law School as a sample", Law Journal, page 36, the first one, 2010.

[4] Liu Xiaoxia editor:m“oot court”, Science Press, page 5 ,the first one, 2010.

[5] Xigen Wang,"The latest American Legal Education Reform and Its Implications - A Harvard University Law School as a sample” , Law Journal, page 137, the first one, 2010 . 